San Jose State University

SJSU ScholarWorks

Master's Theses

Master's Theses and Graduate Research

1991

\title{
A new method of skeletal aging using stages of sacral fusion as seen in the CA-Ala-329 burial population
}

Charlane Susan Gross

San Jose State University

Follow this and additional works at: https://scholarworks.sjsu.edu/etd_theses

\section{Recommended Citation}

Gross, Charlane Susan, "A new method of skeletal aging using stages of sacral fusion as seen in the CAAla-329 burial population" (1991). Master's Theses. 124.

DOI: https://doi.org/10.31979/etd.bazm-b4h7

https://scholarworks.sjsu.edu/etd_theses/124

This Thesis is brought to you for free and open access by the Master's Theses and Graduate Research at SJSU ScholarWorks. It has been accepted for inclusion in Master's Theses by an authorized administrator of SJSU ScholarWorks. For more information, please contact scholarworks@sjsu.edu. 


\section{INFORMATION TO USERS}

This manuscript has been reproduced from the microfilm master. UMI films the text directly from the original or copy submitted. Thus, some thesis and dissertation copies are in typewriter face, while others may be from any type of computer printer.

The quality of this reproduction is dependent upon the quality of the copy submitted. Broken or indistinct print, colored or poor quality illustrations and photographs, print bleedthrough, substandard margins, and improper alignment can adversely affect reproduction.

In the unlikely event that the author did not send UMI a complete manuscript and there are missing pages, these will be noted. Also, if unauthorized copyright material had to be removed, a note will indicate the deletion.

Oversize materials (e.g., maps, drawings, charts) are reproduced by sectioning the original, beginning at the upper left-hand corner and continuing from left to right in equal sections with small overlaps. Each original is also photographed in one exposure and is included in reduced form at the back of the book.

Photographs included in the original manuscript have been reproduced xerographically in this copy. Higher quality $6 "$ x 9 " black and white photographic prints are available for any photographs or illustrations appearing in this copy for as additional charge. Contact UMI directly to order.

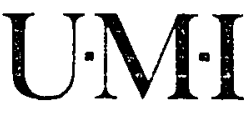

University Microfilms International

A Bell \& Howell Information Company

300 North Zeeb Road. Ann Arbor. MI 48106-1346 USA

$313 / 761-4700 \quad 800: 521-0600$ 
Order Number 1344270

A new method of skeletal aging using stages of sacral fusion as seen in the CA-Ala-329 burial population

Gross, Charlane Susan, M.A.

San Jose State University, 1991

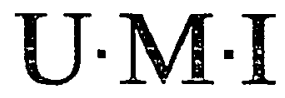

300 N. Zeeb Rd.

Ann Arbor, MI 48106 


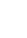


A NEW MFTHOD OF SKELETAL AGING USING STAGES OF SACRAL FUSION AS SEEN IN THE CA-ALA-329 BURIAL POPULATION

\author{
A Thesis \\ Presented To \\ The Faculty of the Department of Social Sciences \\ San Jose State University \\ In Partial Fulfillment \\ of the Requirements for the Degree \\ Master of Arts
}

By

Charlane Susan Gross

May, 1991 
APPROVED FOR THE DEPARTMENT OF SOCIAL SCIENCES

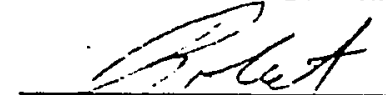

Dr. Robert Jurmain

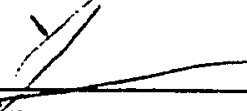

$\frac{\text { FRomis } U \text {. Leyzer }}{\text { Dr. Thomas Layton }}$

James hi. Freewen

Dr. James Freeman

APPROVED FOR THE UNIVERSITY

Serene If teanfore 


\begin{abstract}
A NEW METHOD OF SKELETAL AGING USING STAGES OF SACRAL FUSION AS SEEN IN THE CA-ALA-329 BURIAL POPULATION

by Charlane S. Gross
\end{abstract}

This thesis developed and tested a new method of determining skeletal age at death using fusion of the five sacral vertebrae. Research was conducted or: the CA-Ala-329 burial population currently housed at San Jose State University. The collection totals approximately 440 burials. These were screened for characteristics desirable for this study, reducing the number of burials to 169. The degree of fusion was recorded for each burial at three sites: the transverse processes, the superior and inferior articular facets, and the intervertebral laminae. The data were placed into tables which indicated ages at which substantial changes in the degree of fusion occurred. This information was then given a $\chi^{2}$ test of independence to confirm the significance of the changes at the ages indicated.

The problems and implications of this study were discussed, as well as areas of further research. 


\section{ACKNOWLEDGEMENTS}

First and foremost, I would like to thank the gentlemen of my committee. Dr. Jurmain provided the original suggestions which became the basis for this thesis, and Drs. Jurmain, Layton, and Freeman all contributed tremendous editorial assistance.

Additionally, I am grateful for the use of San Jose State's Human Osteology laboratory and collections.

Special thanks go to Jeff Simon for much-needed and very patient computer assistance, to Brian Ludwig for continual support and encouragement, and to all my family and friends who yelled at me until I finished. 


\section{TABLE OF CONTENTS}

Abstract iii

Acknowledgements iv

CHAPTER PAGE

1 Introduction............................. 1

Skeletal Development and Maturation. .. 4

Development of the Sacrum. ......... 8

2 Materials and Methods..................... 11

Research Population............. 11

Procedure.................... 14

3 Results............................. 17

Females.................... 20

Males........................... 21

4 Discussion............................. 27

Problems with this Method.......... 28

Recommendations for Further Work. . . . 30

APPENDICES

A Burials Used in the Study................... 32

San Jose State University. ........... 33

Stanford University............... 36

B Illustrations of Stages of Sacral Fusion............ 38

Females..................... 39

Males...................... 41

REFERENCES CITED $. \ldots \ldots \ldots \ldots \ldots \ldots \ldots \ldots \ldots \ldots, 44$ 


\section{LIST OF TABLES}

TABLE PAGE

1. Sample Size....................... 16

2. Statistically Significant Stages of Fusion

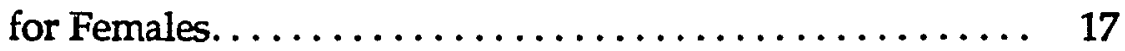

3. Statistically Significant Stages of Fusion for Males. ......................... 19

4. Statistically Significant Stages of Fusion at $25+$ Years. . . . . . . . . . . . . . . 24 


\section{LIST OF FIGURES}

FIGURE

PAGE

1. The Human Skeleton. . . . . . . . . . . . . . . . . . . 6

Embryonic Sacrum

2. Anterior and Posterior Views of the Sacrum....... 7 


\section{CHAPTER 1}

\section{INTRODUCTION}

Ascertaining an individual's age at death is one of the most important determinations made on human skeletal remains. The past century in pariticular has seen a great deal of research towards the definition of ages of skeletal development and maturation processes. Unfortunately, the reliability of this research has been quite variable. One of the earliest of the maturational studies concerned the sternum (Dwight 1890), which was again examined approximately 65 years later (Stewart 1954). Other studies examined the scapula (Graves 1922) and the clavicle (Szilvassy 1980; Webb and Suchey 1985). In the past decade, several research efforts have focused on the ribs (McCormick 1980; Iscan, Loth, and Wright 1984a; 1984b; Iscan, Loth, and Wright 1985). All of the above methods are of little use to osteologists working with Native American populations, either because they are highly inaccurate when applied to non-Europeans, or because they generally reflect changes invisible in dry bone. Indeed, Iscan reports that his aging technique, using changes in the sternal rib end, works on Europeans only (Robert Jurmain, personal communication, April 1991), and Katz and Suchey (1989) reported similar difficulties they attributed to race.

Other techniques have been developed to deal with dry bone. Of these, the most questionable (Singer 1953; Brooks 1955; McKern and Stewart 1957), although of long standing as an aging method, is the closure of the cranial sutures (Dwight 1890; Todd and Lyon 1924; Todd and Lyon 1925a; 1925b; Meindl and Lovejoy 1985). Suture closure was recently re-examined by 
Meindl and Lovejoy (1985). They showed that cranial suture closure can help confirm an age already indicated by other factors.

More effective, particularly in younger individuals (approximately to age 12) are measurements of long bone length (Johnston 1962; Ubelaker 1984). Epiphyseal union is also effective for age determination through the second decade (Stevenson 1924; McKern and Stewart 1957; Johnston 1962), as well as dental eruption and development, also approximately to age 12 (Cattell 1928: Meredith 1946; Gustafson 1950; Miles 1963; Ubelaker 1984). Dental eruption and development are commonly used in conjunction with longbone length and epiphyseal development to assess ages from near birth to the late teens. Longbone growth and development can be influenced by environmental factors such as disease and dietary deficiencies during ontogeny (Degenhardt 1982; Stinson 1985). When examining a skeleton whose growth is incomplete, the investigator must search for Harris' lines, enamel hypoplasias, and other evidence that growth has been interrupted. Dental attrition which occurs at a demonstrably steady rate (Lovejoy 1985), and cementum annulation counts may be used to age adult dentition (Stott, Sis, and Levy 1982).

By far the most valuable technique used to estimate an individual's age, once dental eruption and epiphyseal union are compete, involves gauging age-related changes in the pubic symphyses. The past 70 years have produced several studies of symphyseal changes (Todd 1920; Todd 1921; McKern 1956; McKern and Stewart 1957; Gilbert and McKern 1973; Hanihara and Suzuki 1978; Katz and Suchey 1986). Overall, these studies were focused on males, usually white, taken from coroners' samples. The major exception was the 
study by Gilbert and McKern (1973) which was based upon a sample of 130 females. However, in a test of the reliability of the Gilbert and McKern study, Suchey (1979) had only a 51\% success rate. Meindl et al. (1985) conducted a test of four symphyseal aging methods (Gilbert and McKern, Hanihara and Suzuki, McKern and Stewart, and Todd) on skeletons of known age and found that all the tested systems tended to underage. As a result, they developed a modification of the Todd system. In another test of the reliability of symphyseal aging methods, Katz and Suchey (1989) demonstrated that racial differences caused differences of up to eighteen years in age determinations. Between the years 1986 and 1988, Suchey and Brooks produced a six stage symphyseal aging technique based on a multiracial sample, with separate models for males and females (Suchey, Brooks and Katz 1986; 1988).

A technique similar to the pubic symphysis methods was developed by Lovejoy, et al. (Chronological Metamorphosis, 1985) using changes on the auricular surface. They defined eight stages of development to be used on both sexes and attained a success rate favorably comparable to the use of the Gilbert and McKern and McKern and Stewart pubic symphysis methods.

All of the methods discussed above give only an approximate age at death. In forensic cases involving identification of modern skeletal material this estimated age, together with sex and stature estimates and skeletal and dental anomalies, may identify a specific person, at which time an exact age will be known. However, the researcher will never know the exact age at death of any prehistoric individual; at best an age may be estimated. This estimate is made as accurate as possible by analyzing several areas in 
combination. Lovejoy, et al. (Multifactorial Determination, 1985) combined independent observations on the pubic symphysis, auricular surface, proximal femur, dental wear and suture closure of individuals of known age and proved that a multifactorial approach was far more accurate than any single aging method.

\section{Skeletal Development and Maturation}

In the embryo, the skeleton is formed by two processes, endochondral ossification and intramembranous ossification. Endochondral ossification involves the construction of a cartilage model which becomes vascularized then permeated by osteoblasts laying down a bone matrix beginning at the point of vascularization. The longbones and portions of the cranium are formed in this manner. Endochondral ossification is also associated with the growth of the longbones and fracture healing.

Intramembranous ossification does not involve a preliminary cartilage model of the bone. Rather, a membranous sheet is covered with unmineralized bone matrix (osteoid), which is later mineralized. This process can take only hours in the fetus but may require several months in an adult. The spinal column, pelvic girdle, extremities, and portions of the cranium form in this manner.

After birth, the infant grows very quickly with the femur doubling in length by the fourth year (Ortner and Putschar 1981). Cssification continues as portions of the skeleton form and strengthen. Growth is completed when the epiphyses of the longbones fuse: the epiphyses of the elbow, ankle, and 
hip unite in the mid-teens; the epiphyses of the knee fuse in the mid to late teens; and the wrist and shoulder epiphyses fuse in the late teens.

These ages vary among individuals, but eventually, growth and development are completed, at approximately 20 years old for boys and 16-18 years old for girls (Freiberg 1983). There is a widespread assumption that maies and females mature at different rates which is particularly true for individuals less than 18 months old (Roche, Wainer, and Thissen 1975; Freiberg 1983). This generality holds true until around the sixth year. Both sexes have a pubertal growth spurt which occurs an average of two years earlier in females, making them temporarily more skeletally mature and taller than males (Freiberg 1983). When boys finally begin their growth spurt they tend to surpass females, eventually expressing adult levels of sexual dimorphism (Hebbelinck and Borms 1984). Environmental stresses may, of course, retard normal growth and development patterns, and there is some evidence that males may be slightly more affected by these factors than females (Stinson 1985). Figure 1 contains an illustration of the aduit skeleton from Bass (1987).

Most of the age-related research has, noticeably, not focused on skeletal maturation in the prehistoric American Indian. The difficulty in developing an accurate and reliable technique for a population for which we have little demographic information is obvious. To compensate for the lack of data to develop skeletal aging techniques specifically for prehistoric Native Americans, methods were developed through study of modern individuals then applied to archaeological samples.

For several reasons, the sacrum has rarely been the focus of researchers 
Figure 1. Top The Human Skeleton Bottom, The Fetal Sacrum

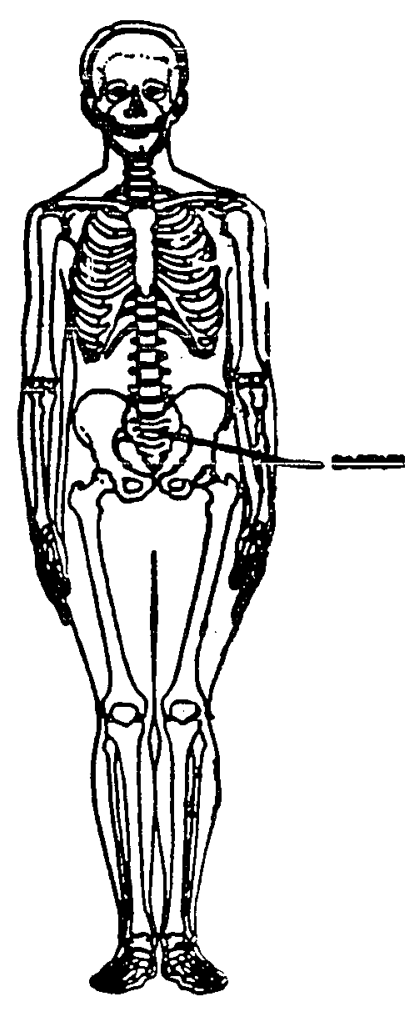

$s$ Prinary canters
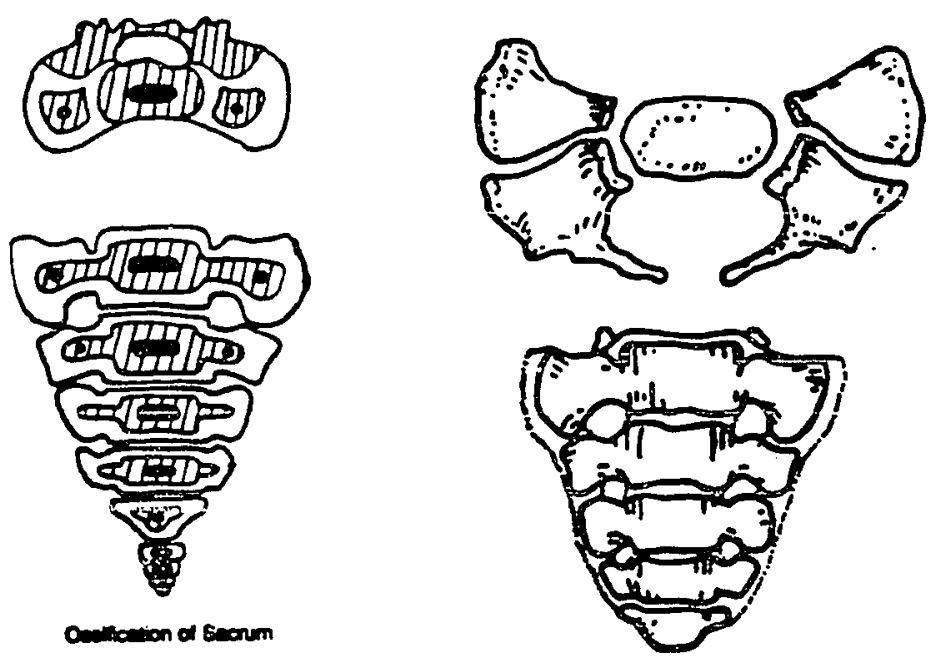

seconm a wa 4 
Figure 2. Top Adult Sacrum, Anterior View

Bottom, Adult Sacrum, Posterior View
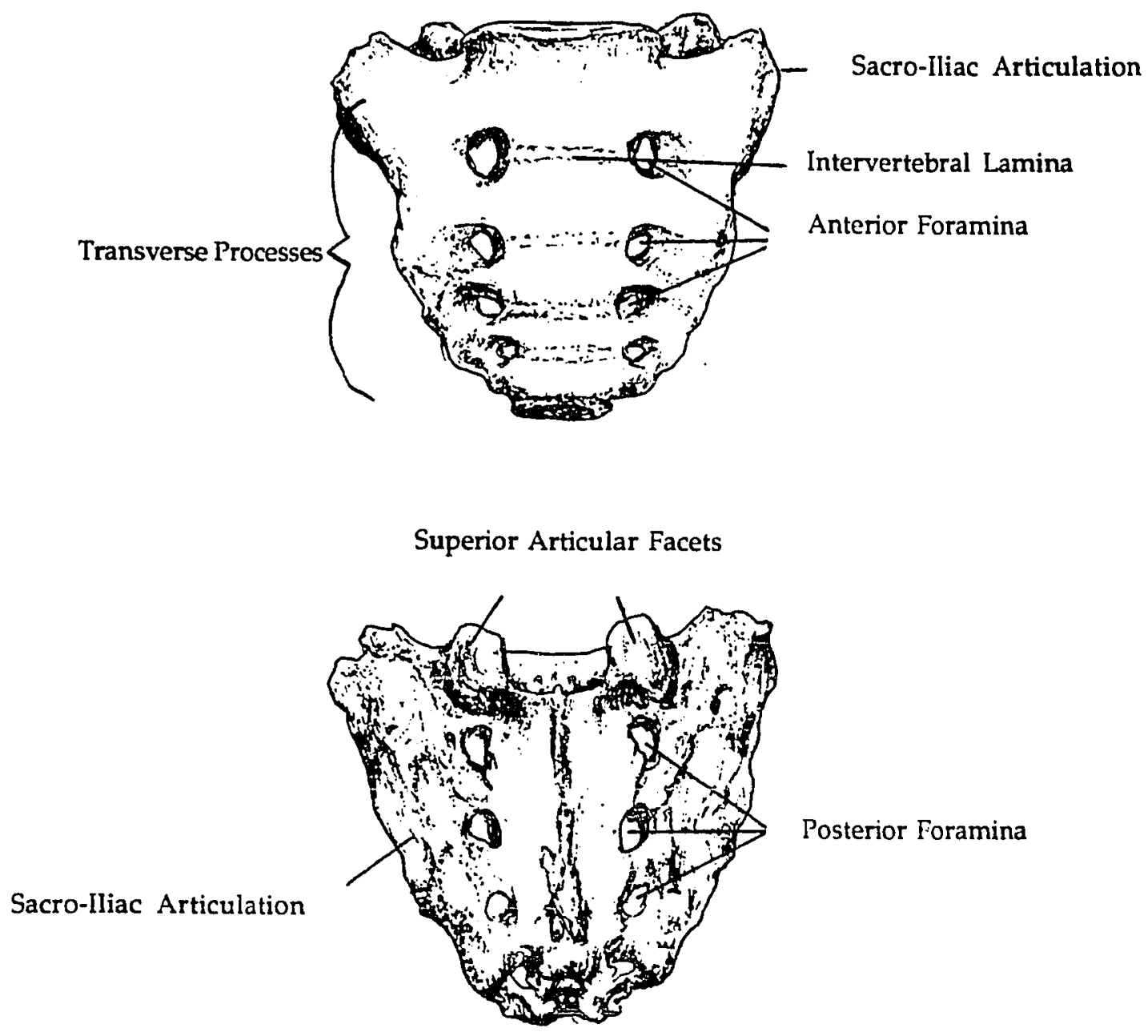
trying to establish skeletal aging methods. Because of its lack of cortical bone, the sacrum generally is not well preserved under archaeological conditions, and there are ofher osteological indicators of age which can be far more regular in their development, e.g. the pubic symphyses, the auricular surfaces, dental eruption and development, and epiphyseal fusion.

\section{Development of the Sacrum}

The sacrum is a wedge-shaped bone at the base of the spinal column. It is, in actuality, composed of five elongated vertebrae which fuse together into a single bone in the first thirty years of life. The sacrum is the transfer point of upper body weight to the lower limbs - the upper body weight is transmitted down the spinal column to the sacrum. The stability of the L5/S-1 joint is provided by the wide bodies of the last lumber and first sacral centra resting on each other anteriorally, and the two pairs of articular facets posteriorally, linked together by fibrous cartilage. The sacrum then transfers the weight laterally to the os coxae. The sacro-iliac articulation is a synovial joint; the joint surfaces are covered by smooth hyaline cartilage which allows some movement, although less than in other synovial joints. From the sacro-iliac articulation, weight travels along the iliac pillar of the os coxae to the acetabulae, through to the femoral heads, and down through the legs.

In the embryo, the neural tube becomes enclosed by skeletogenic mesenchyme cells alternating with spinal ganglia. The result is a series of disconnected areas of hyaline cartilage which will become vertebral bodies after intermembranous ossification. Other cartilaginous areas nearby become the neural arches and spinous processes for each vertebra (Balinsky 1981; 
Ortner and Putschar 1981). Like other vertebrae, each sacral vertebra has three primary centers of ossification, one in the body and one in each of the two lateral portions (Bass 1987), with two additional lateral ossification centers for each of the upper three sacral vertebrae. Ossification of the bodies of the sacral vertebrae begins at the end of the first trimester of pregnancy and the pedicles ossify in the $6-8$ th months of fetal life at which time the lateral masses appear. The laminae and arches conjoin in the first two years and these fuse to the bodies of the lower vertebrae between the second and sixth years. The upper vertebrae do not complete this process until the fifth or sixth year (Gray 1977). Figure 1 contains an illustration of the fetal sacrum.

Before the five sacral vertebrae fuse together, they are separated by intervertebral disks like those found in the rest of the vertebral column. However, these disks ossify at the time of fusion and become part of the intervertebral laminae (Trotter and Peterson 1966). The exact ages of the ankylosis of the sacral vertebrae will be discussed below.

Use of the sacrum as an indicator of age apparently has only been investigated as part of maturational studies of the entire body, such as one would find in a general anatomy text like that by Henry Gray (1977) or in mataturational surrveys of the skeletorn, as in MícKern and Stewart (1957). A limitation of these studies is that they were conducted in dissection rooms and, therefore, on modern populations. Gray's data were collected at a medical school, and McKern and Stewart's study used Korean War dead. Later works simply refer to the above studies, particularly McKern and Stewart, when discussing sacral aging, either for forensic or archaeological specimens (Krogman 1978; Brothwell 1981; Bass 1987). This thesis tests the 
accuracy of the generalization stated in Gray (1977) and in McKern and Stewart (1957) that sacral fusion progresses cranially, that is, that fusion of the five sacral vertebrae begins in the lower vertebrae and ends in the upper vertebrae, and that this occurs between the ages 18-30. McKern and Stewart do give specific ages for the fusion of the bodies of the sacral vertebrae: the mid-twenties for the lower vertebrae, and ages $26-30$ for the S1-2 union. They also contend that the transverse processes, or lateral masses, are fully united by age 22 , as are the lateral epiphyses for the sacro-iliac articulation.

Otherwise, these studies give little detail about the exact progression of fusion. Figure 2 contains illustrations of the adult sacrum from Bass (1987). 


\section{CHAPTER 2}

\section{MATERIALS AND METHODS}

\section{Research Population}

In this study, a previously examined archaeological population from Northern California was used to develop and test a technique using the fusion of the five sacral vertebrae to determine skeletal age at death. Separate stages of fusion were defined according to ages at which they occurred in the Native American burials from CA-Ala-329.

CA-Ala-329 is located in the Coyote Hills near the southeastern end of San Francisco Bay. During its occupation, the site lay near the edge of the Bay, although as a result of siltation, the site now lies approximately three miles from the shore (Davis and Treganza 1959; Jurmain 1990).

A series of radiocarbon dates demonstrate that the site was continuously occupied from ca. $550 \mathrm{AD}$ to ca. $1700 \mathrm{AD}$ (Alan Leventhal, personal communication, October 1990), a time when the area was a giant estuary lined with salt marshes (Coberly 1973; Desgrandchamps 1976). Alameda Creek was probably a perennial stream less than three miles from the site (Bickel 1981). Additionally, there were fresh water springs nearer the site that have since dried out. The abundant resources provided by this environment drew Costanoan Indians back to the area repeatedly, and over the course of approximately 1,150 years, a sizeable mound accumulated.

About 500 burials were removed from CA-Ala-329 between 1958 and 1968 primarily by San Jose State University and Stanford University field 
classes. Eventually, most of the burials were temporarily brought together at San Jose State University where the research for this thesis was conducted.

Overall, the collection was in an excellent state of preservation, demonstrated by the fact that there were over forty-five infants ( $<2$ years old) recovered. This is the portion of the population most likely to be underrepresented since many infant bones are incompletely calcified and usually disintegrate rapidly after burial (Gordon and Buikstra 1981). Of the approximately 440 burials at San Jose State University, 169 skeletons were found to have sacra suitable for this analysis.

All individuals with either no sacrum or a highly fragmentary sacrum. were first eliminated from the total sample. Individuals below 6 years of age were also eliminated, as the elements of each sacral vertebra are not always fused before that age.

Individuals above age 14 with fewer than three sacral yertebrae remaining were also eliminated from the sample as they were judged too incomplete for proper analysis and thus might give undue weight to the importance of the superior portion of the sacrum, the section most commonly preserved. Below age 14, individuals with two or more sacral vertebrae were retained in the study because of the paucity of burials between ages 6 and 14. Elimination of burials between ages 6-14 with fewer than three vertebrae would have reduced the sub-sample by $20 \%$.

The burials were then grouped by sex: male, female, and indeterminate. Sex was determined independently by two researchers ( $R$. Jurmain and $R$. Gillett) using a combination of criteria including characteristics of the pelvis 
and cranium, and metrical analyses based on the 1986 study by Dittrick and Suchey (Gillett 1987).

Because males and females mature at different rates, they were analyzed separately. Even after the completion of growth, the body continues to develop, and it was felt that differing developmental rates based on gender might affect the sacrum. Individuals of indeterminate sex above age 14 were eliminated because they could not be placed into a category.

The last category of sacra eliminated consisted of those with no bracketing ages. These were individuals that could be assigned no range of age at death (e.g. 25 to 35 years) but rather were given open ended ranges (e.g. 25 years or more). Because of the method used for initial development of this technique, it was necessary to determine the mean age of each individual in the sample. Those without bracketing ages were eliminated because no mean age could be calculated. Different manipulations of the data might allow use of individuals with only a minimum estimated age, however.

The burials from CA-Ala-329 were assigned ages by two independent researchers ( $R$. Jurmain and R. Gillett) using a variety of techniques (Gillett 1987). The primary method used was the Suchey-Brooks pubic symphysis aging sets for male (1986) and female (1988). Other techniques used were dental development, eruption, and wear, epiphyseal development and fusion and, to a lesser extent, arthritic degeneration and cranial suture closure. Each burial used in this study is listed in Appendix A with its Seex, age, and mean age. 


\section{Procedure}

Once the total CA-Ala-329 sample of sacra was examined and reduced to those useable for this study, those remaining were divided into three categories: male $(N=97)$, female $(N=63)$, and indeterminate $(N=12)$. The mean age of each burial was calculated by taking the midpoint of the age range assigned to the skeleton and rounding off to the nearest integer if necessary. Next, the degree of fusion was recorded for both of the transverse articulations on each vertebra, as was the amount of fusion on the superior and inferior articular facets of each vertebra. The development of the laminal ring between the vertebrae, closure of its ventral surface, and the presence of the lateral epiphyses were also noted. The degree of fusion was recorded in different ways for each of the articular surfaces. The amount $10 \%$ was chosen as a minimum limit of fusion because it indicates only the beginnings of fusion, and $80 \%$ was chosen as an intermediate limit because it indicates significant fusion activity without ankylosis being complete. The degree of fusion was assessed macroscopically and without measuring instruments but was checked for internal consistency by constant comparisons against previously assessed surfaces thus assuring continuity.

The transverse surfaces were recorded as not fused, slightly fused (less than $10 \%$ of the surface was ankylosed), partly fused (10-80\% surface ankylosis), mostly fused (greater than $80 \%$ ), and completely fused. The degree of fusion was easily quantified because once begun, it appeared to occur so rapidly that transverse surfaces displayed either very little evidence of activity or significant activity with very few intermediate stages; the fusion process 
also completed quickly, again leaving little room for error. The inferior and superior articular facets were recorded as not fused, partly fused (up to $80 \%$ surface ankylosis), and completely fused. There are fewer categories for the facets than for the transverse surfaces, as the facets have much smaller surfaces. Thus, it was far more difficult to determine the amount of fusion that had taken place especially as the view of the facet was somewhat obscured by its angle in the articulated sacrum.

The laminae circling each vertebral body were recorded as: absent; present but with the ring incomplete; and complete. Additionally, the articulations with complete laminal rings were scored by whether or not the gap between the laminae of adjacent vertebrae was open or closed on the ventral face of the sacrum.

The data from the sacra were tabulated for easier analysis. Each of the three major areas of analysis (transverse processes, articular facets, and intervertebral laminae) were grouped together, so that three tables were constructed for each individual, with the vertical section indicating each vertebra, and the horizontal indicating the degree of development and fusion. These tables were arranged in order of age and by sex. Visual examination of the tables and rote familiarization with them showed clear increases in maturity by certain ages. The smaller numbers of younger individuals made this task much easier. Based on this examination, the skeletons were divided into the groups seen in Table 1. 
Table 1.--Sample Size

$\begin{array}{lcr} & \text { Age Groups } & \mathrm{N}= \\ \text { Females } & \leq 18 & 5 \\ & 19-24 & 12 \\ & 25-30 & 13 \\ & 31-36 & 10 \\ \text { Males } & & \\ & \leq 18 & 18 \\ & 19-24 & 13 \\ & 25-30 & 16 \\ & 31-36 & 22\end{array}$

Each of these age groupings was then given a $\chi^{2}$ test of independence using $2 \times 4$ contingency tables for the transverse processes and $2 X 3$ contingency tables for the articular facets and inter-vertebral laminae. The degree of fusion at each of the three areas was tested against the same area in the next oldest age group using a minimum significance level $p=.05$ and the differences thereby determined to be statistically significant or not.

Sample Table.--Articular Facets in Females $\begin{array}{llll}\text { Age Group } & \text { not } & \text { partly } & \text { completely } \\ \text { fused } & \text { fused } & \text { fused }\end{array}$ $\leq 18$ 19-24 


\section{CHAPTER 3}

\section{RESULTS}

The results of statistical analyses indicate that it is possible to assign minimum or maximum ages for the fusion of the transverse processes, articular facets, and intervertebral laminae. Fusion in other parts of the sacrum occurs either so gradually or at such varied ages that no accurate assessment of age could be given. Tables 2 and 3 present these findings.

Table 2.--Statistically Significant Stages of Fusion for Females

$$
\begin{aligned}
& \text { Age group Comparisons } \\
& \frac{\leq 18(n=5)}{19-24(n=12)} \quad \frac{19-24(n=12)}{25-30(n=13)} \quad \frac{25-30(n=13)}{31-36(n=10)}
\end{aligned}
$$

Transverse Surfaces

$\begin{array}{ll}\text { S1-2 } & \text { X(.01) } \\ \text { S2-3 } & \text { X(.01) } \\ \text { S3-4 } & - \\ \text { S4-5 } & -\end{array}$

Superior and Inferior

Articular Facets

$\mathrm{S} 1-2 \quad-$

S2-3 -

S3-4 -

S4-5 -

Intervertebral Laminae

$\begin{array}{llll}\text { S1-2 } & X(.05) & - & X(.05) \\ \text { S2-3 } & - & - & - \\ \text { S3-4 } & X(.05) & - & - \\ \text { S4-5 } & - & - & -\end{array}$

$X$ indicates a statistically significant level ( $\leq .05)$; the level of significance appears in parentheses after an $X$. 
This table and the ones following are meant to provide a minimum and maximum possible age for a sacrum. The first step is to determine the sex of the individual. Next, inspect the three main areas listed in each table: transverse surfaces, articular facets, and laminae, then compare the sacrum in question with the tables and the accompanying descriptions. If, for example, the sacrum in question is from a female and the S1-2 and S2-3 transverse processes are only partially fused and the S3-4 and S4-5 processes completely fused, by reading the tables and noting that the S1-2 and S2-3 transverse processes are significant areas of discrimination and checking those areas in the descriptions, the researcher can determine that the individual is probably $\leq 18$ years old. The descriptions indicate that the completion or nearcompletion of fusion of S1-2-3 transverse processes mark the division between the two categories, with a lower degree of fusion indicating the younger age group.

In another example, if the sacrum is male, all transverse surfaces and articular facets completely fused, and the laminal rings are completely formed, but gaps between the S1-2 and S2-3 rings remain open on the ventral face of the sacrum, then the individual is 19-24 years old. Table 3 and the accompanying description show that a fully developed laminal ring makes the individual $>18$ years old. Table 4 shows that the closure of these two gaps (S1-2, S2-3) indicates an individual $>25$ years old. Since the gaps are still open, the sacrum in question will be 19-24 years old. If the gaps had closed, the estimated age would be over 30 years old - again as can be seen in Table 3 .

The illustrations in Appendix B will aid in identifying specific stages of fusion. 
Table 3.--Statistically Significant Stages of Fusion for Males

Age Group Comparisons

$$
\frac{<18(\mathrm{n}=18)}{19-24(\mathrm{n}=13)} \quad \frac{19-24(\mathrm{n}=13)}{25-30(\mathrm{n}=16)} \quad \frac{25-30(\mathrm{n}=16)}{31-36(\mathrm{n}=22)}
$$

Transverse Surfaces

$\begin{array}{ll}\text { S1-2 } & X(.01) \\ \text { S2-3 } & X(.01) \\ \text { S3-4 } & X(.025) \\ \text { S4-5 } & X(.01)\end{array}$

Superior and Inferior

Articular Facets

$\begin{array}{ll}\text { S1-2 } & X(.01) \\ \text { S2-3 } & - \\ \text { S3-4 } & - \\ \text { S4-5 } & X(.025)\end{array}$

Intervertebral Laminae

$\begin{array}{llll}\text { S1-2 } & X(.025) & - & X(.01) \\ \text { S2-3 } & X(.025) & - & - \\ \text { S3-4 } & X(.01) & - & - \\ \text { S4-5 } & X(.05) & - & X(.01)\end{array}$

$X$ indicates a statistically significant level $(\leq .05)$; the level of significance appears in parentheses after an $X$.

As can be seen from the tables for both the males and females, the most common age distinction is made between the early to mid teens and the late teens, with clear age distinctions between only two other groups in the 31-36 range for both the males and females. A summary of each stage appears at the beginning of its description in the following sections. 


\section{Females}

The females were sub-divided into four age categories: $\leq 18 ; 19-24 ; 25-30$;

and 31-36. Age 14 is the youngest at which there were definite sexual determinations on any of the female skeletons. The age categories were defined by separating the sample where there appeared to be sufficient maturational change as to warrant a new group; moreover, intervals of similar length were created when sufficient changes to define a new category were not as evident. After age 36, the sacra were uniformly completely mature, with $4 \%$ of females retaining the laminal gap between S1-2.

The females showed significant differences between the $\leq 18$ and 19-24 groups at four locations: the transverse processes between S1-2 and S2-3; and the lamina between S1-2 and S3-4.

1) S1-2-3 transverse processes: partly fused $<18$, completely fused 19-24

In the transverse process between $51-2$, in the group $\leq 18$, none of the surfaces were completely fused. They were only partially fused, and in one individual, the surface had not begun to fuse at all. In the 19-24 group, however, two-thirds of the individuals had completely fused transverse processes and the other third had over $80 \%$ of the surface between the processes fused together. The transverse processes between S2-3 were similar. Of the $\leq 18$ group, only one individual's processes were completely fused; the other four were $10-70 \%$ fused. In the 19-24 group 73\% of the individuals had completely fused processes, and the remaining $27 \%$ were over $80 \%$ fused. The other transverse processes as well as all the articular facets consistently 
fused at so young an age as to be unusable as an age indicator after the midteens.

2) S1-2 laminae: partially formed $<18$, complete but open 19-24

S1-2 laminae: complete but open $<30$, closed $>30$

In $80 \%$ of the cases, the intervertebral laminae between S1-2 for group $\leq 18$ were only partially formed if at all, whereas in the $19-24$ group, $82 \%$ of individuals had fully formed laminae, but retained the gap between the rings. Closure of this gap on the anterior surface of the sacrum was the division between the 25-30 and 31-36 groups of females.

3) S3-4 laminae: partially formed $<18$, complete but open 19-24

A similar situation occurred regarding the development of the laminae between S3-4 in the $\leq 18$ and 19-24 groups. Approximately $80 \%$ of the $\leq 18$ group had no or only partial development of the laminae, whereas all of the 19-24 group had full development; $68 \%$ had already filled in the gap between the rings.

\section{4) Sacro-iliac surfaces: fused hv 20}

One additional indicator of minimum age was the appearance and fusion of the lateral articular surfaces for the sacro-iliac joint, where the epiphyses begin appearing in the late teens and are completely fused by age 20 .

\section{Males}

The males were divided into the same age categories as the females: $\leq 18$; 19-24; 25-30; and 31-36. 12 years was the age of the youngest male to be positively identified as to sex. Like the females, the age categories for males were demarcated where substantial maturational changes to warrant a 
different group were made and also intentionally keeping the age range intervals similar when the changes did not justify a new group. After age 36, the sacra were almost uniformly completely mature, with $5 \%$ of males retaining a S1-2 laminal gap.

The males showed maturational distinctions between the $\leq 18$ and 19-24 groups in ten different categories: the transverse processes between S1-2, S2-3, S3-4, and S4-5; the articular facets between S1-2 and S4-5; and the intervertebral laminae between S1-2, S2-3, S3-4, and S4-5.

1) S1-2 transverse processes: partially fused $<18$, completely fused 19-24

None of the $\leq 18$ group had the S1-2 transverse processes completely fused. In the 19-24 group only one individual's S1-2 transverse processes were not completely fused.

2) S2-3-4-5 transverse processes: partially fused $<18$, completely fused 19-24

The degree of fusion of the transverse processes of S2-3, S3-4, and S4-5 was similar to the S1-2 between the $\leq 18$ and 19-24 groups, although the $\leq 18$ group showed slightly more fusion between S2-3 than S1-2 and slightly more fusion in S3-4 than in S2-3, but all were still significantly less mature than the same surfaces in the 19-24 group.

3) S1-2, S4-5 articular facets: partially fused <18, completely fused 19-24

The articular facets between S1-2 and S4-5 for the group $\leq 18$ were only completely fused in $21 \%$ of individuals, but were completely fused in $91 \%$ of the 19-24 group.

4) S1-2-3-4-5 laminae: partially formed $<18$, complete but open 19-24

All the intervertebral laminae were non-existent or only partially completed in $62 \%$ of cases in the $\leq 18$ group. The $19-24$ group shows $95 \%$ of 
individuals had fully developed laminae, although the gap between the rings remained open in approximately $50 \%$ of the individuals.

5) S1-2, S4-5 laminae: complete but open $<30$, closed $>30$

The closure of the remaining laminal gap distinguished an additional age group. The laminae between S1-2 and S4-5 filled in by age 30 in almost all cases. In approximately $8 \%$ of cases, the S1-2 gap appears as though it would never have completely filled in. However, at that point in skeletal development, other age determination techniques may reliably be used.

6) Sacro-iliac surfaces: fused by 21

Additionally, minimum age could be determined by the fusion of the lateral epiphyses for the sacro-iliac joint. They began to appear in the late teens and fused completely by age 21 .

Appendix B contains illustrations of the sacra at significant stages of fusion.

Because there were significant changes at the $20+$ and $31+$ ages, but nowhere in between (e.g., 25+), and it was deemed desirable to have additional definable ages, the data were reanalyzed in two groups for each sex: $\leq 24$ years old, and 25-36. By regrouping the individuals into these categories, larger comparative groups were created, thus helping to control for sampling error due to small sample size, and with a resultant increase in the number of identifiably significant stages, as shown in Table 4. 
Table 4.--Statistically Significant Stages of Fusion at 25+ Years

$\begin{array}{ll}\text { Females } & \text { Males } \\ \frac{\leq 24(n=17)}{25-36(n=23)} & \frac{<24(n=31)}{25-36(n=37)}\end{array}$

Transverse Surfaces

$\begin{array}{lll}\text { S1-2 } & X(.025) & X(.01) \\ \text { S2-3 } & - & X(.01) \\ \text { S3-4 } & - & X(.01) \\ \text { S4-5 } & - & X(.025)\end{array}$

Superior and Inferior

Articular Facets

$\begin{array}{lll}\text { S1-2 } & X(.01) & X(.01) \\ \text { S2-3 } & - & - \\ \text { S3-4 } & - & - \\ \text { S4-5 } & X(.05) & -\end{array}$

Intervertebral Laminae

$\begin{array}{lll}\text { S1-2 } & - & X(.01) \\ \text { S2-3 } & X(.01) & X(.01) \\ \text { S3-4 } & X(.025) & X(.01) \\ \text { S4-5 } & - & X(.01)\end{array}$

$X$ indicates a statistically significant stage. The significance level is noted in parentheses.

The females still showed far fewer identifiable stages of fusion than the males, but five significant fusion stages were determined: one in the transverse processes; two among the articular facets; and two in the intervertebral laminae.

1) S1-2 transverse process: partially fused $<24$, completely fused $>25$

The S1-2 transverse process was completely fused in only $47 \%$ of individuals $\leq 24$, but was completely fused in all individuals in the 25-36 range. 
2) S1-2, S4-5 articular facets: partially fused $<24$, completely fused $>25$

Only $38 \%$ of the S1-2 articular facets in females were completely fused in skeletons $\leq 24$, but $96 \%$ were fused in skeletons $25-36$ years old. Similarly, $67 \%$ of females $\leq 24$ had completely fused S4-5 facets and $95 \%$ of $25-36$ females had completely fused facets.

3) S2-3 laminae: incomplete or open $<24$, closed $>25$

S3-4 laminae: open $<24$, closed $>25$

The intervertebral laminae in the S2-3 of females were only partially formed or remained open in $56 \%$ of individuals $\leq 24$, but were completely closed in $100 \%$ of the $25-36$ group. Only $50 \%$ of females had closed the S3-4 lantinal gap in the $\leq 24$ group, but again the gap was $100 \%$ ciosed in the $25-36$ group.

The males showed significant differences between the $\leq 24$ and 25-36 age groups in nine areas: four in the transverse processes; one in the articular facets; and four more among the intervertebral laminae.

1) S1-2-3-4-5 transverse processes: partially fused $<24$, completely fused $>25$

The transverse processes between all the sacral vertebrae ranged from $37 \%-61 \%$ completely fused $(\mathrm{S} 1-2=43 \%, \mathrm{~S} 2-3=37 \%, \mathrm{~S} 3-4=42 \%$, and S4-5 $=$ $61 \%$ ) in the $\leq 24$ group, but were $100 \%$ fused in the 25-36 group of males.

2) S1-2 articular facets: partially fused $<24$, completely fused $>25$

The S1-2 articular facets were not fused or only partially fused in $54 \%$ of males $\leq 24$ but $83 \%$ were completely fused by the ages of 25-36.

\section{3) S1-2 laminae: gaps open $<24$, closed $>25$}

Only $7 \%$ of the males $\leq 24$ had closed the gaps between the S1-2 laminae. By $25-36,59 \%$ had closed the gaps. As discussed previously, in several cases it 
appeared as though this gap might remain permanently open, so the figure $59 \%$ actually should be higher, since it represents the end of fusion at that locus. In practical applications, however, it may be difficult to determine whether a gap between the S1-2 laminae is a result of as-yet unfinished fusion processes or an anomaly of some sort.

4) S2-3-4-5 laminae: gaps open $<24$, closed $>25$

The gaps between S2-3, S3-4, and S4-5 showed similar development from $\leq 24$ to the $25-36$ age group in males: S2-3 increased from $29 \%$ to $95 \%$ closed; S3-4 progressed from $42 \%$ to $97 \%$ closure rate; and S4-5 had 32\% closed gaps $\leq 24$ and $83 \%$ closed in the 25-36 group.

See Appeidix B for illustrations of sacra at significant stages. 


\section{CHAPTER 4}

\section{DISCUSSION}

The somewhat limited utility of the sacrum for skeletal aging has been demonstrated in Tables 2, 3, and 4. Its usefulness lies mainly in differentiating the late teens from the early twenties and the mid twenties from the late twenties age groups. Prior to the late teens, the development of the various sacral elements and their pattern of fusion is too unpredictable to be useful indicators of anything more than a very general age group, i.e. the early to mid-teens. Once the individual has reached the age 20 , the fusion of two pairs of the transverse surfaces, two pairs of articular facets, and development of three of the laminal rings demonstrate consistent age-related changes in the female, and fusion of all four pairs of transverse surfaces, two pairs of articular facets, and development of all four of the laminal rings indicate consistent age-related changes in the male. There were over twice as many statistically identifiable age breaks for the males as there were for the females. The fusion of the feniale sacrum tended to occur at an earlier age than the male and more gradually, so that there were few abrupt transitions at any identifiable age for the females.

Because there are many good osteological age indicators throughout the years of growth and development, the fact that the sacrum is somewhat ineffective until nearly the end of this process is of no real import. It is at this juncture in skeletal development, when the rapid growth of the body has diminished, longbone epiphyseal fusion and dental eruption are nearly complete, and the indicators of more advanced age (e.g., pubic symphyses) 
have not yet developed sufficiently, that the sacrum becomes a valuable tool in age determination. Unfortunately, the sacrum's usefulness declines by the end of the twenties. However, by that age changes in the pubic symphyseal face and auricular surface become the preferred methods of age determination.

One of the goals of this research was to test the commonly held assumption that sacral fusion occurs cranially, which has been shown to be only partially true. There is a slight tendency for the sacral vertebrae to begin to fuse together loosely in that order, but the process is not necessarily completed in the same order.

The transverse processes of the females do tend to completely fuse in the lower three vertebrae first, but the fusion completes in the S1-2-3 joins at approximately the same age, rather than $51-2$ being the last to fuse. The articular facets unite almost as soon as the transverse processes. The transverse processes of the males complete their fusion in the late teens to early twerties in no particular order. The uprermost and lowermost pairs of articular facets are the last to completely fuse. In females, the gap between the S1-2 laminae is the last to close, but the others are filled in in no significant order. The S1-2 and S4-5 laminal gaps both are open until the thirties in the males, again not conforming to the cranial fusion pattern.

\section{Problems with this Method}

A major problem with this method is that it requires an individual of known sex. The tables clearly indicate that maie and female sacra mature at different rates. The fusion of transverse processes of both appear to 
differentiate the $\leq 18 / 19+$ division, but the other areas are not in such concordance. In fact, this $\leq 18 / 19+$ demarcation seems to be the most common area of age differentiation within the sacrum.

During the course of this paper, ages have been discussed with some precision for the sake of convenience, but in practical applications, the researcher using this technique should recall that this process was developed using the mean age of each skeleton rather than a range of ages in which the skeleton was likely to fall. Thus, it should be assumed that the age divisions listed in Tables 2, 3, and 4 are not concrete boundaries. Also, even though a range of ages was calculated into which each individual was likely to fall, there is a degree of uncertainty about the individual's age, because the skeletons are from a prehistoric population and there is always the possibility that the skeleton does not fall into or even close to the age range assigned to it. Additionally, there is an equal chance that the skeleton was at every age in the range originally given to it - so the mean age may actually be quite different from the actual age, especially if the age range is a large one. The tables in this paper allow five or more years of leeway for each skeleton, but for use with a specific individual, the investigator may wish to expand the range based on other aging criteria.

Intra-populational variation must also be taken into account. This process was developed on a specific genetic population undergoing specific environmental stresses. Possibly no other populations were genetically and environmentally similar enough to this one that it could be assumed that growth and development of the individuals closely matched that from CAAla-329. Therefore, it is recommended that, when applying this aging 
method to a population which is not a temporal, geographic, and possibly genetic neighbor of CA-Ala-329, the researcher first conduct a test of the accuracy of the age tables in this report on the population in question. The investigator should first make the most accurate age determinations possible on adults of known sex and calculate their mean ages. Next, the sacra of those individuals should be examined and the following information recorded: degree of fusion at the transverse processes; degree of fusion at the superior and inferior articular facets; and development and closure of the intervertebral laminae. The researcher should then examine the data to determine whether the different development and fusion events occur with any regularity as to age, e.g. $90 \%$ of the S1-2 transverse processes are completely fused by age 22 . This way, the investigator can develop a sacral fusion table which is calibrated for the specific population being examined. Once this table is completed, it can be used on individuals with relatively complete sacra but who cannot be aged by other methods, or in confirmation of a hypothesized age determination.

\section{Recommendations for Further Work}

Thus far, this paper has discussed the use of the sacral fusion aging method as a technique for use with prehistoric burials. However, there also is a great potential for use of this process with modern populations. In fact, it would be much more accurate when used on a modern population since, during the tailoring of this technique for a specific population as discussed in the previous section, one would not have to use an estimated mean age. Instead, the researcher could construct the tables by using coroners' 
populations with known age, sex, and race, thus specifically controlling many of the possible variables. The age groupings might also be manipulated, as well as how the data are recorded; e.g., recording such aspects as fused/not fused, instead of attempting to rate stages of fusion. The development of these modern population tables, because they would be based on known-age individuals would, in fact, confirm the reliability of this process, since it would remove the inaccuracy introduced by using estimated ages. This seems to be the logical next step of this study, in that it would add further credibility to the sacral fusion aging method and simultaneously increase the specific applications of the technique.

After the construction of these tables, the sacrum might prove a highly valuable identification aid in some sort of mass disaster. It is buried fairly deeply in the body, which would afford some protection and increase its chance for survival. Even without knowledge of the sex of the individual in question, the sacrum would show whether that person was $<19$ years old by an overall lack of fusion found in both sexes, or $>30$ years old by a complete fusion of the sacrum, also found in both sexes. If the individual's sex can be determined, then the sacrum's age discrimination potential would become even more distinct.

The usefulness of the sacrum as an indicator of skeletal age at death is only one method of age determination. All aging methods have their weaknesses and this one is no exception, but it fits into an age gap which other techniques leave open, and thus becomes an important new tool for the osteologist. 
APPENDIX A 
San Jose State University Burials

\begin{tabular}{|c|c|c|c|}
\hline Burial \# & Sex & Age & Mean Age \\
\hline 1 & M & $35-45$ & 40 \\
\hline 3 & $\mathbf{M}$ & $35-44$ & 39.5 \\
\hline 5 & $\mathrm{M}$ & $26-35$ & 30.5 \\
\hline 6 & $\mathrm{~F}$ & $21-30$ & 25.5 \\
\hline 7 & F & 14 & 14 \\
\hline 10 & $\mathbf{M}$ & $35-44$ & 39.5 \\
\hline 12 & $\mathrm{~F}$ & $39-44$ & 41.5 \\
\hline 14 & $\mathbf{M}$ & $31-40$ & 35.5 \\
\hline 16 & $\mathbf{M}$ & $31-40$ & 35.5 \\
\hline 17 & Indet. & $5-7$ & 6 \\
\hline 18 & $\mathbf{M}$ & $17-18$ & 17.5 \\
\hline 19 & $\mathbf{M}$ & $35-45$ & 40 \\
\hline 20 & $\mathrm{~F}$ & $19-24$ & 21.5 \\
\hline 21 & $\mathbf{M}$ & $30-35$ & 32.5 \\
\hline 22 & $\mathrm{~F}$ & $39-44$ & 41.5 \\
\hline 23 & $\mathbf{M}$ & $30-40$ & 35 \\
\hline 24 & $\mathbf{M}$ & $20-24$ & 22 \\
\hline 25 & $\mathrm{~F}$ & $35-44$ & 39.5 \\
\hline 31 & $\mathbf{M}$ & $27-35$ & 31 \\
\hline 36 & $\mathbf{M}$ & $35-44$ & 39.5 \\
\hline 39 & $M$ & $27-35$ & 31 \\
\hline 48 & $\mathbf{M}$ & $30-39$ & 34.5 \\
\hline 50 & $\mathbf{M}$ & $31-35$ & 33 \\
\hline 51 & F & $39-44$ & 41.5 \\
\hline 53 & $\mathbf{M}$ & $17-21$ & 19 \\
\hline 54 & F & $35-44$ & 39.5 \\
\hline 58 & $\mathbf{M}$ & 25-35 & 30 \\
\hline 62 & F & $31-40$ & 35.5 \\
\hline 63 & $\mathbf{M}$ & $13-15$ & 14 \\
\hline 64 & $\mathbf{M}$ & $30-39$ & 34.5 \\
\hline 65 & $\mathbf{M}$ & $35-39$ & 37 \\
\hline 66 & $\mathrm{~F}$ & $31-41$ & 35.5 \\
\hline 69 & $\mathbf{M}$ & $25-34$ & 29.5 \\
\hline 70 & $\mathrm{M}$ & $16-18$ & 17 \\
\hline 71 & $\mathbf{M}$ & $31-40$ & 35.5 \\
\hline 74 & $\mathrm{~F}$ & $35-44$ & 39.5 \\
\hline 78 & $\mathbf{M}$ & $35-44$ & 39.5 \\
\hline $88 \mathrm{~A}$ & $\mathrm{~F}$ & $41-50$ & 45.5 \\
\hline 89 & $\mathbf{M}$ & $12-15$ & 13.5 \\
\hline
\end{tabular}




\begin{tabular}{|c|c|c|c|}
\hline Burial \# & Sex & Age & Mean Age \\
\hline 92 & $\mathrm{~F}$ & $20-24$ & 22 \\
\hline 93 & $\mathrm{~F}$ & $39-44$ & 41.5 \\
\hline 94 & $\mathrm{M}$ & $21-30$ & 25.5 \\
\hline 96 & $F$ & $35-45$ & 40 \\
\hline 97 & $\mathbf{M}$ & $35-50$ & 42.5 \\
\hline 99 & $\mathbf{M}$ & $35-44$ & 39.5 \\
\hline 100 & $\mathbf{M}$ & $41-50$ & 45.5 \\
\hline 101 & F & $13-15$ & 14 \\
\hline 102 & $\mathrm{M}$ & $21-30$ & 25.5 \\
\hline 103 & $\mathbf{M}$ & $31-40$ & 35.5 \\
\hline 106 & $\mathbf{M}$ & $31-40$ & 35.5 \\
\hline 107 & Indet. & $6-7$ & 6.5 \\
\hline 108 & $\mathrm{~F}$ & $31-40$ & 35.5 \\
\hline 109 & $\mathbf{M}$ & $27-35$ & 31 \\
\hline 111 & $\mathrm{~F}$ & $31-40$ & 35.5 \\
\hline 113 & F & $18-21$ & 19.5 \\
\hline 114 & F & $13-15$ & 14 \\
\hline 115 & $\mathbf{M}$ & $16-18$ & 17 \\
\hline 118 & F & $35-39$ & 37 \\
\hline 119 & $\mathbf{M}$ & $16-18$ & 17 \\
\hline 124 & $\mathrm{~F}$ & $16-18$ & 17 \\
\hline 125 & $\mathrm{M}$ & $25-40$ & 32.5 \\
\hline 126 & Indet. & $8-13$ & 10.5 \\
\hline 127 & $\mathbf{M}$ & $16-18$ & 17 \\
\hline 132 & F & $31-40$ & 35.5 \\
\hline 133 & F & $35-44$ & 39.5 \\
\hline 135 & $\mathbf{M}$ & $39-44$ & 41.5 \\
\hline 136 & $\mathrm{M}$ & $35-44$ & 39.5 \\
\hline 142 & $\mathrm{~F}$ & $20-23$ & 21.5 \\
\hline 143 & F & $25-30$ & 27.5 \\
\hline 146 & $\mathrm{~F}$ & $21-30$ & 25.5 \\
\hline 148 & Indet. & $12-15$ & 13.5 \\
\hline 150 & $\mathbf{M}$ & $27-30$ & 28.5 \\
\hline 151 & $\mathrm{M}$ & $27-35$ & 31 \\
\hline 152 & $\mathbf{M}$ & $12-14$ & 13 \\
\hline 153 & $\mathrm{~F}$ & $17-20$ & 18.5 \\
\hline 158 & F & $25-39$ & 32 \\
\hline 161 & $\mathbf{M}$ & $21-35$ & 28 \\
\hline 162 & $\mathrm{M}$ & $20-22$ & 21 \\
\hline 163 & $\mathrm{~F}$ & $39-50$ & 44.5 \\
\hline 167 & F & $30-40$ & 35 \\
\hline
\end{tabular}




\begin{tabular}{|c|c|c|c|}
\hline Burial \# & Sex & Age & Mean Age \\
\hline 170 & Indet. & $6-8$ & 7 \\
\hline 173 & $\mathrm{M}$ & $25-35$ & 30 \\
\hline 177 & $\mathbf{M}$ & $39-44$ & 41.5 \\
\hline 180 & $\mathrm{M}$ & $41-50$ & 45.5 \\
\hline 183 & $\mathrm{~F}$ & $30-39$ & 34.5 \\
\hline 184 & $\mathrm{~F}$ & $18-25$ & 21.5 \\
\hline 185 & $\mathrm{M}$ & $13-15$ & 14 \\
\hline 186 & $\mathbf{M}$ & $30-39$ & 34.5 \\
\hline 191 & $\mathbf{M}$ & $18-25$ & 21.5 \\
\hline 201 & $\mathbf{M}$ & $39-44$ & 41.5 \\
\hline 202 & $\mathbf{M}$ & $19-21$ & 20 \\
\hline 209 & $\mathbf{F}$ & $18-22$ & 20 \\
\hline 211 & F & $21-30$ & 25.5 \\
\hline 216 & $M$ & $39-50$ & 44.5 \\
\hline 217 & $\mathrm{~F}$ & $39-44$ & 41.5 \\
\hline 218 & $\mathrm{M}$ & $41-50$ & 45.5 \\
\hline 225 & $\mathrm{M}$ & $35-45$ & 40 \\
\hline $227 \mathrm{~A}$ & $\mathbf{M}$ & $21-30$ & 25.5 \\
\hline 230 & $\mathbf{M}$ & $31-45$ & 38 \\
\hline 235 & $\mathbf{F}$ & $22-24$ & 23 \\
\hline 238 & $\mathbf{F}$ & $30-39$ & 34.5 \\
\hline 239 & $\mathbf{M}$ & $18-25$ & 21.5 \\
\hline 242 & $\mathrm{M}$ & 35.44 & 39.5 \\
\hline 243 & $\mathbf{M}$ & $35-44$ & 39.5 \\
\hline 244 & $M$ & $39-44$ & 41.5 \\
\hline 245 & $\mathrm{M}$ & $31-40$ & 35.5 \\
\hline 249 & $M$ & $35-44$ & 39.5 \\
\hline 250 & F & $16-18$ & 17 \\
\hline 251 & $\mathrm{~F}$ & $25-35$ & 30 \\
\hline 256 & $\mathbf{M}$ & $30-40$ & 35 \\
\hline 257 & $\mathrm{~F}$ & $20-30$ & 25 \\
\hline 259 & $\mathbf{M}$ & $12-14$ & 13 \\
\hline 260 & $\mathbf{M}$ & $21-25$ & 23 \\
\hline 261 & $\mathrm{~F}$ & $21-35$ & 28 \\
\hline 265 & $\mathrm{M}$ & $14-16$ & 15 \\
\hline 266 & $\mathrm{~F}$ & $39-44$ & 41.5 \\
\hline 267 & $\mathbf{M}$ & $16-18$ & 17 \\
\hline 268 & $\mathbf{M}$ & $17-21$ & 19 \\
\hline 269 & $F$ & $30-45$ & 37.5 \\
\hline 270 & Indet. & $6.5-8.5$ & 7.5 \\
\hline 273 & $\mathbf{M}$ & $31-40$ & 35.5 \\
\hline
\end{tabular}




$\begin{array}{llll}\text { Burial \# } & \text { Sex } & \text { Age } & \text { Mean Age } \\ 275 & \text { F } & 39-44 & 41.5 \\ 276 & \text { F } & 41-50 & 45.5 \\ 278 & \text { F } & 35-50 & 42.5 \\ 282 & \text { F } & 31-44 & 37.5 \\ 283 & \text { M } & 14-18 & 16\end{array}$

\begin{tabular}{|c|c|c|c|}
\hline Burial \# & $\begin{array}{c}\text { Stanf } \\
\text { Sex } \\
\end{array}$ & $\begin{array}{r}\text { Irials } \\
\text { Agge }\end{array}$ & ivīeân Áge \\
\hline 3 & F & $35-44$ & 39.5 \\
\hline 6 & $\mathbf{M}$ & $31-44$ & 37.5 \\
\hline 7 & $\mathbf{M}$ & $21-35$ & 28 \\
\hline 12 & F & $25-35$ & 30 \\
\hline 19 & $\mathbf{M}$ & $21-30$ & 25.5 \\
\hline 21 & $\mathbf{M}$ & $27-30$ & 28.5 \\
\hline 24 & $\mathbf{M}$ & $35-50$ & 42.5 \\
\hline 26 & $\mathrm{~F}$ & $25-40$ & 32.5 \\
\hline 27 & $\mathbf{F}$ & $25-35$ & 30 \\
\hline 28 & $\mathrm{~F}$ & $40-50$ & 45 \\
\hline 30 & $\mathrm{~F}$ & $19-25$ & 22 \\
\hline 33 & $\mathrm{~F}$ & $21-30$ & 25.5 \\
\hline 38 & $\mathrm{~F}$ & $21-30$ & 25.5 \\
\hline 40 & Indet. & $12-14$ & 13 \\
\hline 42 & $\mathbf{M}$ & $11.5-12.5$ & 12 \\
\hline 54 & Indet. & $5-7$ & 6 \\
\hline 55 & $\mathbf{M}$ & $17-21$ & 19 \\
\hline 56 & M & $35-50$ & 42.5 \\
\hline 60 & $M$ & 25-35 & 30 \\
\hline 68 & $\mathrm{~F}$ & $19-30$ & 24.5 \\
\hline 69 & $\mathrm{~F}$ & $17-21$ & 19 \\
\hline 70 & $\mathbf{M}$ & $15-17$ & 16 \\
\hline 72 & M & $31-40$ & 35.5 \\
\hline 75 & $\mathrm{~F}$ & $16-21$ & 18.5 \\
\hline 76 & Indet. & $11-13$ & 12 \\
\hline 78 & $\mathbf{M}$ & $20-30$ & 25 \\
\hline 80 & $\mathrm{~F}$ & $21-30$ & 25.5 \\
\hline 83 & $\mathrm{~F}$ & $35-50$ & 42.5 \\
\hline 84 & $\mathrm{M}$ & $31-40$ & 35.5 \\
\hline 90 & $\mathbf{M}$ & $35-44$ & 39.5 \\
\hline 97 & $\mathrm{M}$ & $18-22$ & 20 \\
\hline
\end{tabular}




\begin{tabular}{llll} 
Burial \# & Sex & Age & Mean Age \\
\hline $102 \mathrm{~A}$ & & & \\
108 & $\mathrm{M}$ & $16-21$ & 18.5 \\
109 & $\mathrm{M}$ & $18-35$ & 26.5 \\
111 & $\mathrm{M}$ & $16-21$ & 18.5 \\
113 & $\mathrm{~F}$ & $18-30$ & 24 \\
118 & M & $30-45$ & 37.5 \\
119 & Indet. & $8-11$ & 9.5 \\
120 & Indet. & $8-11$ & 9.5 \\
125 & M & $35-50$ & 42.5 \\
126 & $\mathrm{M}$ & $18-25$ & 21.5 \\
130 & $\mathrm{M}$ & $35-44$ & 39.5 \\
137 & $\mathrm{M}$ & $13-15$ & 14 \\
& $\mathrm{M}$ & $21-30$ & 25.5
\end{tabular}


APPENDIX B 
Females - Increasing Fusion of Transverse Processes and Development of Intervertebral Laminae (Anterior View)

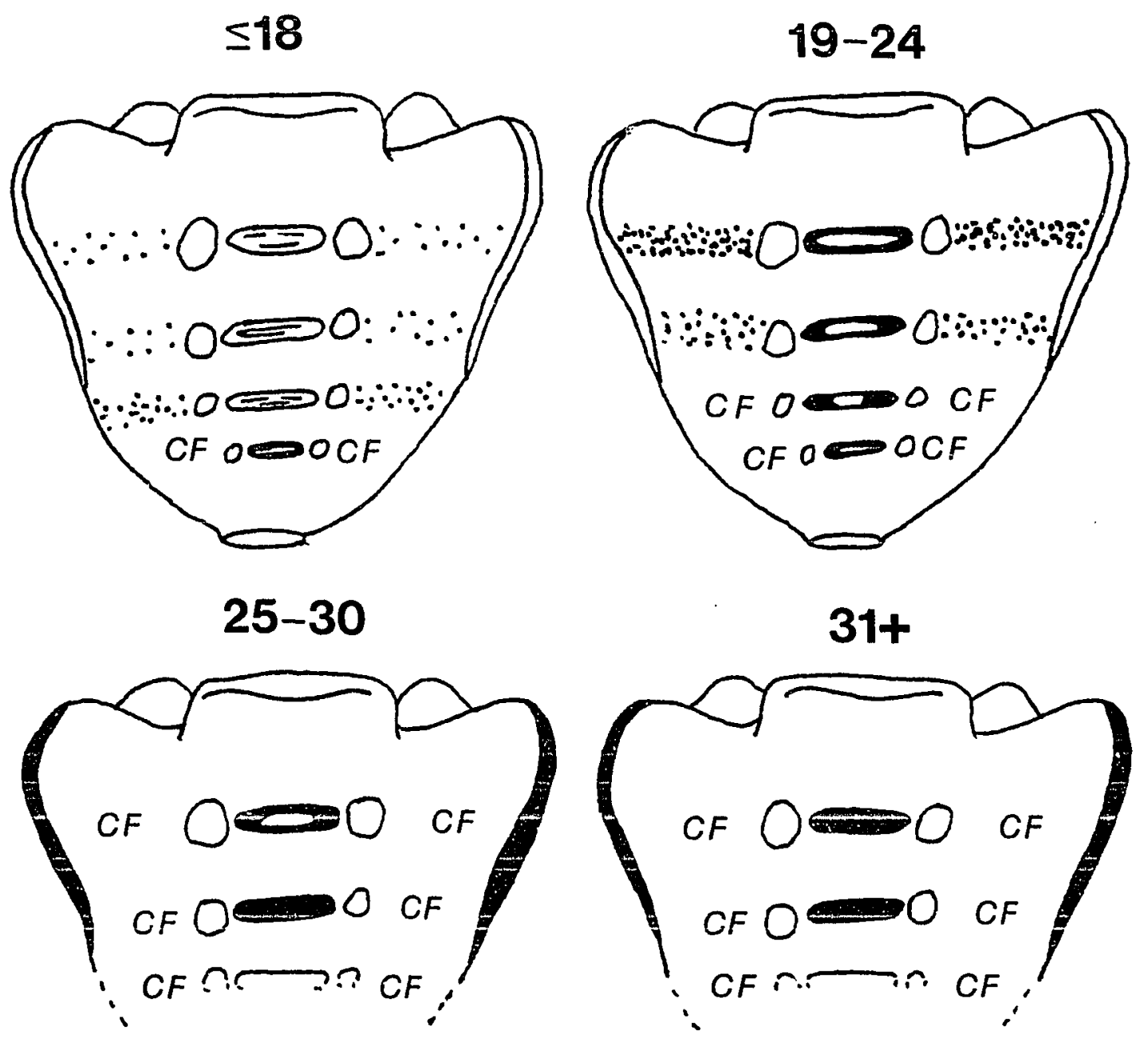

Increased density of stippling indicates increased fusion

CF - completely fused 
Females - Increasing Development of Intervertebral Laminae and Fusion of Articular Facets (Posterior View)
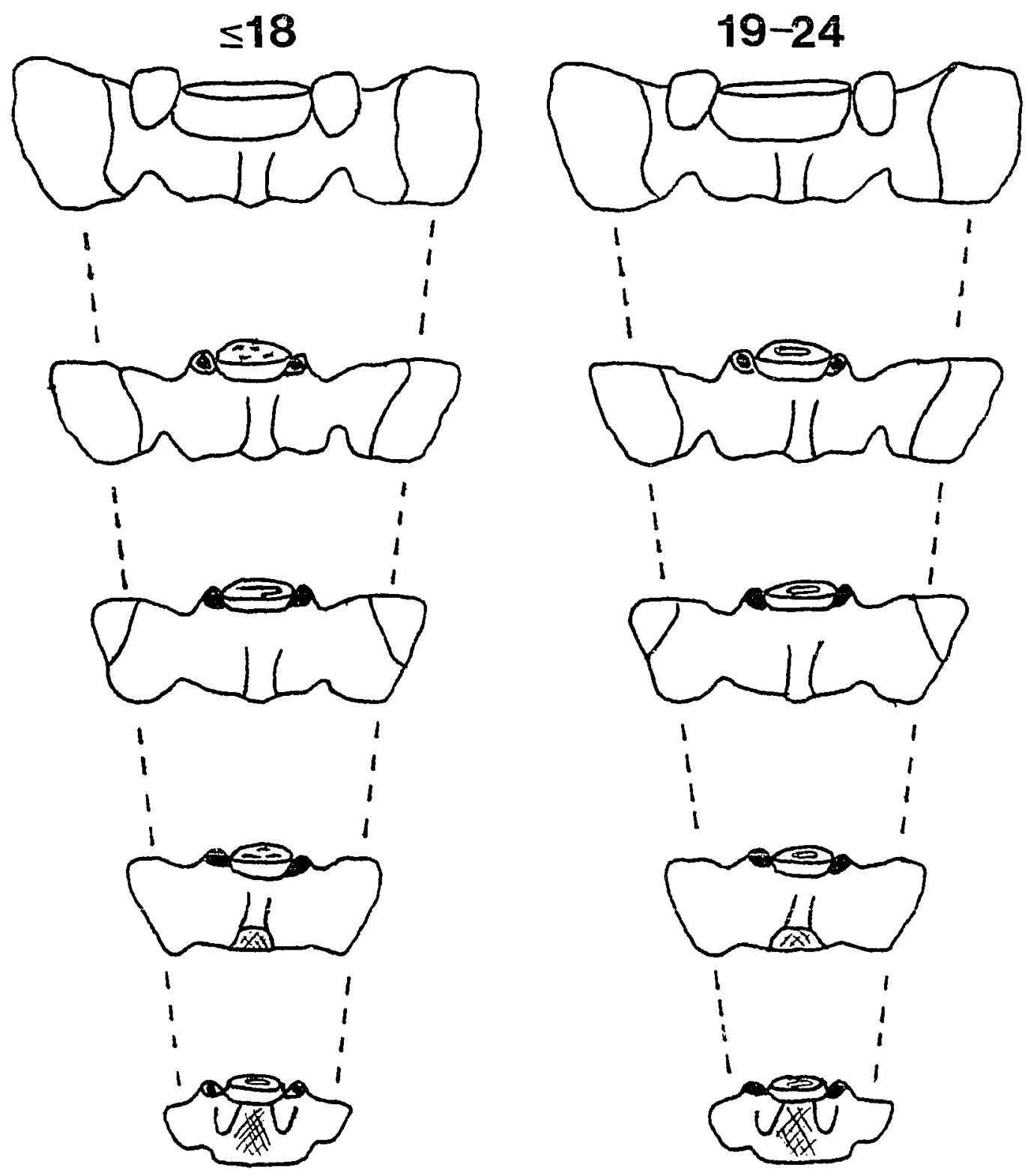

Shading indicates increased fusion 
Males - Increasing Fusion of Transverse Processes and Development of Intervertebral Laminae (Anterior View)
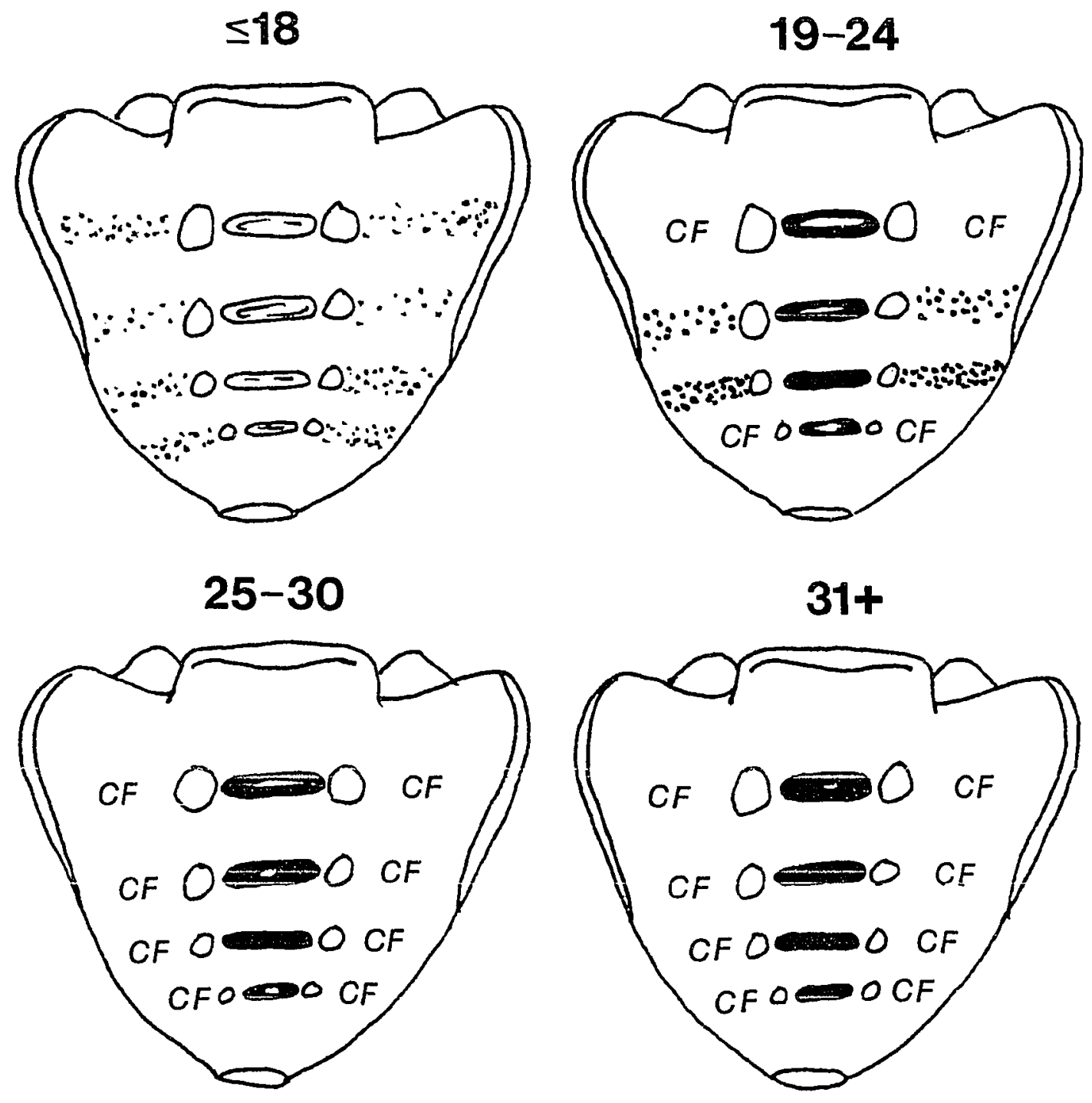

Increased density of stippling indicates increased fusion

CF - completely fused 
Males - Increasing Development of Intervertebral Laminae and Fusion of Articular Facets (Posterior View)
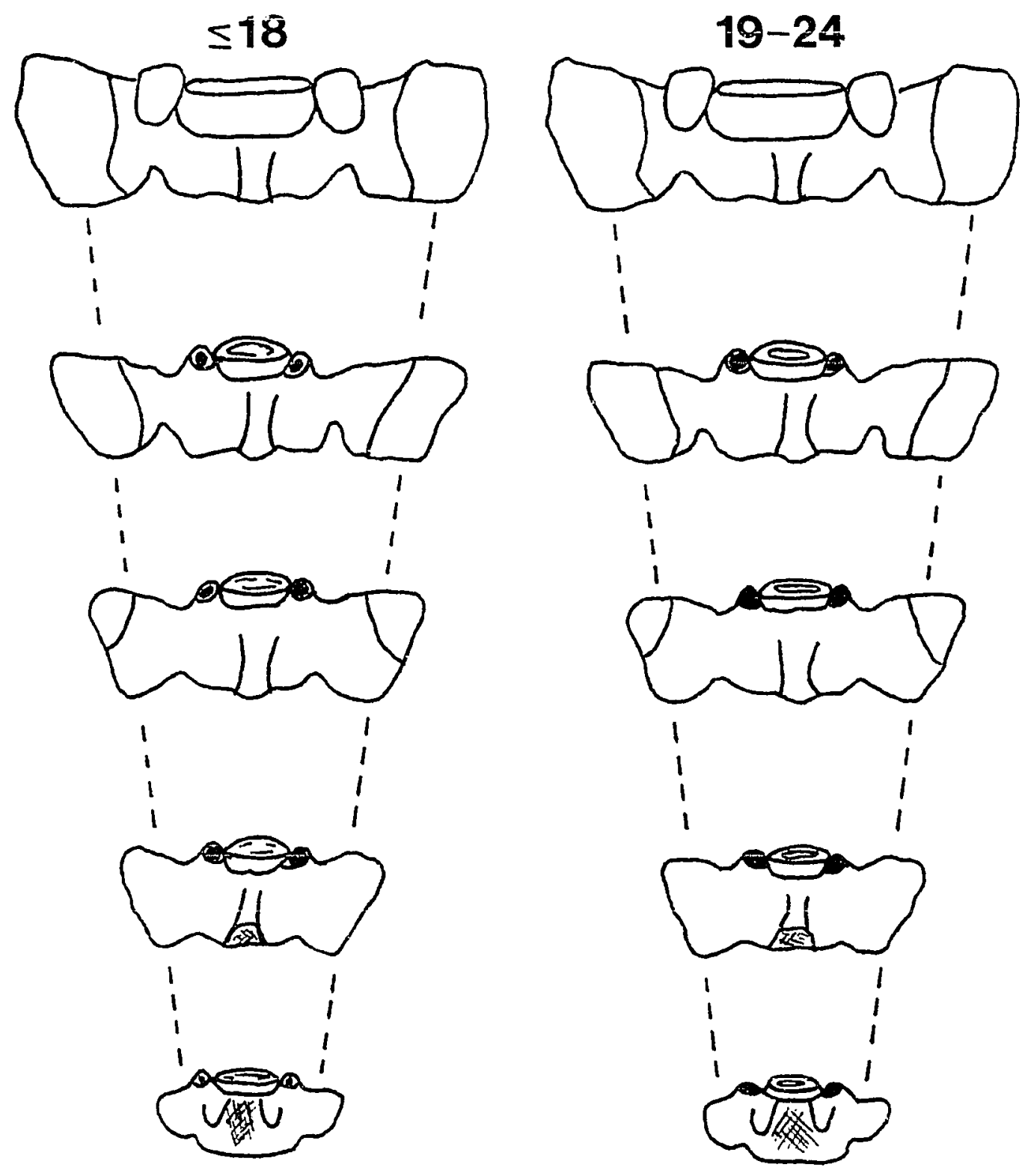

Shading indicates increased fusion 
Males - Increasing Development of Intervertebral Laminae and Fusion of Articular Facets (Posterior View)

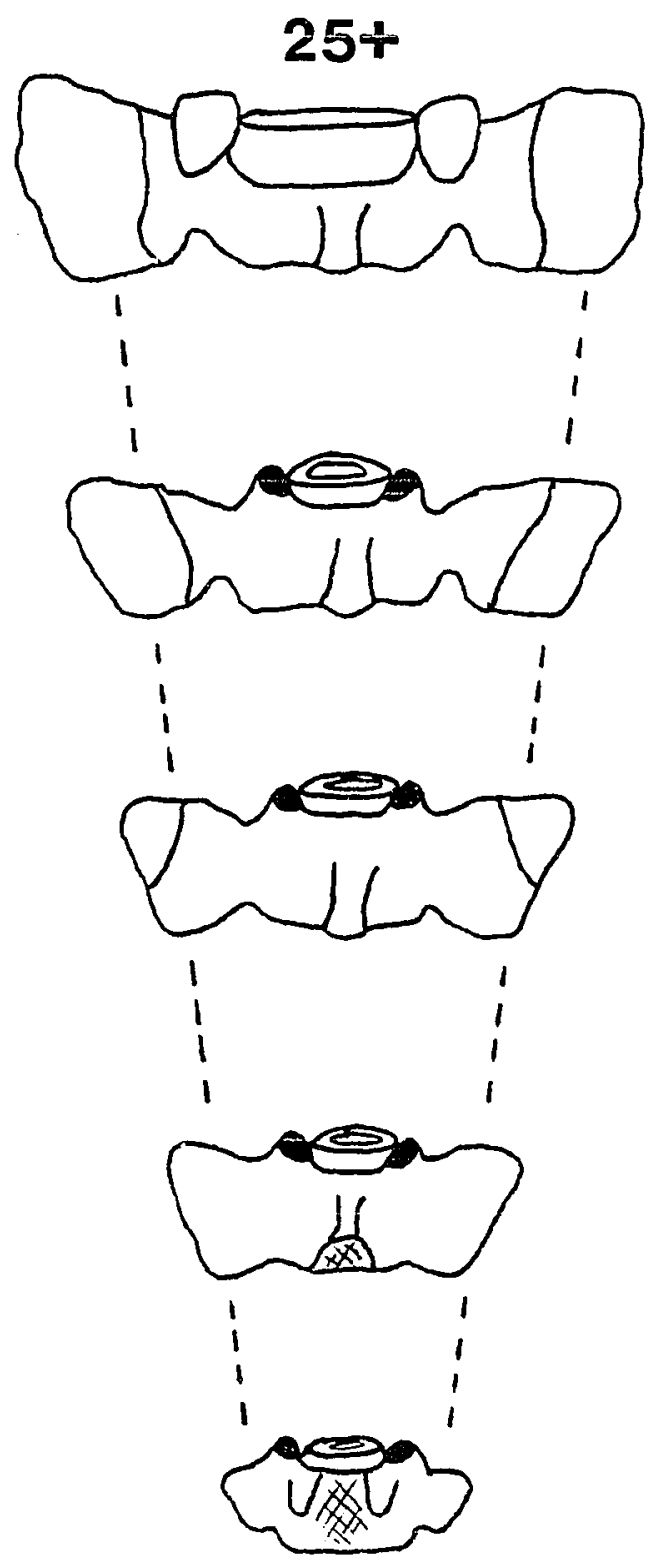

Shading indicates increased fusion 


\section{References Cited}

Bass, W. M. 1987. Human Osteology: a laboratory and field manual of the human skeleton. 3rd ed. Columbia, Missouri: Missouri Archaeological Society.

Balinsky, B. I. 1981. An Introduction to Embryology. 5th ed. New York, New York: Saunders College Publishing.

Bickel, P. McW. 1981. San Francisco Bay archaeology: sites Ala-328, Ala-13 and Ala-12. Berkeley: Contributions of the University of California Archaeological Research Foundation.

Brooks, S. T. 1955. Skeletal age at death: The reliability of cranial and pubic age indicators. Am. I. Phys. Anthropol. 13: 567-597.

Brothwell, D. R. 1981. Digging Up Bones. 3rd ed. Ithaca, New York: Cornell University Press.

Cattell, P. 1928. Dentition as a Measure of Maturity. Cambridge, Mass.: Harvard University Press.

Coberly, M. 1973. The archaeology of the Ryan Mound, site Ala-329, a central California coastal village site. University of Colorado, Museum of Anthropology, Occasional Publications in Anthropology, Archaeology series 4 .

Davis, J. T., and A. E. Treganza. 1959. The Patterson Mound: a comparative analvsis of the archaeology of site Ala-328. Reports of the University of California Archáeological Survey, No. 47.

Degenhardt, A. 1982. Sex differences in physical development of children: Skeletal maturity and development of deciduous teeth as indicators for sex - related growth patterns. L. Hum. Evol. 11: 681-686.

Desgrandchamp, C. S. 1976. Estuary exploitation in aborigional California. Master's Thesis, San Francisco State University.

Dittrick, J., and J. M. Suchey. 1986. Sex determination of prehistoric central California skeletal remains using discriminant analysis of the femur and humerus. Am. I. Phys. Anthropol. 70: 33-9. 
Dwight, T. 1890. The closure of the cranial sutures as a sign of age. Boston Med. and Surg. I. CXXII: 389-392.

Dwight, T. 1890. The sternum as an index of sex, height and age. I. Anat. and Physiol. 24: 527-535.

Freiberg, K. L. 1983. Human Development: A Life-span Approach. 2nd ed. Monterey, Ca: Wadsworth Health Sciences Division.

Gilbbert, B. M., and T. W. McKern. 1973. A method for aging the female os pubis. Am. I. Phys. Anthropol. 38: 31-38.

Gillett, R. M. 1987. Comparative aging techniques as applies to the paleodemography of CA Ala-329. Master's Thesis, San Jose State University.

Gordon, C. G., and J. E. Buikstra. 1981. Soil pH, bone preservation, and sampling bias at moriuary sites. Am. Antiquity. 46: 566-571.

Graves, W. W. 1922. Observations on age changes in the scapula: a preliminary report. Am. I. Phys. Anthropol. 5: 21-31.

Gray, H. 1977. Gray's Anatomy. 15th ed. New York: Bounty Books.

Gustafson, G. 1950. Age determination on teeth. I. Am. Dental Assoc. 41: 45-54.

Hanihara, K. and T. Suzuki, T. 1978. Estimation of age from the pubic symphysis by means of multiple regression analysis. Am. I. Phys. Anthropol. 48: 233-240.

Hebbelinck, M., and J. Borms. 1984. Sexual dimorphism in body build of 6-13 year - old boys and girls. In Human Growth and Development, ed. J. Borms, R. Hauspie, A. Sand, C. Susanne, and M. Hebbelinck, 287-301. New York: Plenum Press.

Iscan, M. Y., S. R. Loth, and R. K. Wright. 1984a. Age estimation from the rib by phase analysis: white males. I. Forensic Sciences 29: 1094-1104.

Iscan, M. Y., S. R. Loth, and R. K. Wright. 1984b. Metamorphosis at the sternal rib end: A new method to estimate age at death in white males. Am. I. Phys. Anthropol. 65: 147-156. 
Iscan, M. Y., S. R. Loth, and R. K. Wright. 1985. Age estimation from the rib by phase analysis: white females. I. Forensic Sciences 30: 853-863.

Johnston, F. E. 1962. Growth of the long bones of infants and young children at Indian Knoll. Human Biology 23: 66-81.

Jurmain, R. D. 1990. Paleoepidemiology of a central California prehistoric population from Ca-Ala-329: Dental disease. Am. I. Phys. Anthropol. 81: 333-342.

Katz, D., and J. M. Suchey. 1986. Age determination of the male os pubis. Am. I. Phys. Anthropol. 69: 427-435.

Katz, D., and J. M. Suchey. 1989. Race differences in pubic symphyseal aging patterns in the male. Am. I. Phys. Anthropol. 80: 167-182.

Krogman, W. M. 1978. The Human Skeleton in Forensic Medicine 3rd ed. Springfield, Illinois: Charies C Thomas.

Lovejoy, C. O. 1985. Dental wear in the Libbon population: Its functional pattern and role in the determination of adult skeletal age at death. Am. I. Phys. Anthropol. 68: 47-56.

Lovejoy, C. O., R. S. Meindl, R. P. Mensforth, and T. J. Barton. 1985a. Multifactorial determination of skeletal age at death: A method and blind tests of its accuracy. Am. I. Phys. Anthropol. 68: 1-14.

Lovejoy, C. O., R. S. Meindl, T. R. Pryzbeck, and R. P. Mensforth,. 1985b. Chronological metamorphosis of the auricular surface of the ilium: A new method for the determination of adult skeletal age at death. Am. I. Phys. Anthropol. 68: 15-28.

McCormick, W. F. 1980. Mineralization of the costal cartilages as an indication of age: Preliminary observations. I. of Forensic Sciences 25: 736-741.

McKern, T. W. 1956. The symphyseal formula: a new method for determining age from pubic symphyses. Am. I. Phys. Anthropol. 14: 388.

McKern, T. W., and T. D. Stewart. 1957. Skeletal age changes in young American males. Natick, Mass. Quartermaster Research and Development Center Environmental Protection Research Division, Technical Report EP-45. 
Meindl, R. S., and C. O. Lovejoy. 1985. Ectocranial suture closure: A revised method for the determination of skeletal age at death based on the lateral anterior sutures. Am. I. Phys. Anthropol. 68: 57-66.

Mieindl, R. S., C. O. Lovejoy, R. P. Mensforth, and R. A. Walker. 1985. A revised method of age determination using the os pubis with a review and tests of accuracy of other current methods of pubic symphyseal aging. Am. I. Phys. Anthropol. 68: 29-45.

Meredith, H. V. 1946. Order and age of eruption for the deciduous dentition. I. Dental Res. 25: 43-66.

Miles, A. E. W. 1963. Dentition in the estimation of age. I. Dental Res. 42: 255-263.

Ortner, D. J., and W. G. J. Putschar . 1981. Identification of Pathological Conditions in Human Skeletal Remains. Washington, D. C.: Smithsonian Institution Press.

Roche, A. F., H. Wainer, H., and D. Thissen. 1975. Skeletal Maturity: the knee joint as a biological indicator. New York: Plenum Medical Book Company.

Singer, R. 1953. Estimation of age from cranial suture closure. I. Forensic Med. 1: 52-59.

Stevenson, P. H. 1924. Age order of epiphyseal union in man. Am. I. Phys. Anthropol. 7: 53-93.

Stewart, T. D. 1954. Metamorphosis of the joints of the sternum in relation to age changes in other bones. Am. I. Phys. Anthropol. 12: 519-535.

Stinson, S. 1985. Sex differences in environmental sensitivity during growth and development. In Yearbook of Phys. Anthropol., 28: 123-147.

Stott, G. G., R. F. Sis, and B. M. Levy. 1982. Cementum annulation as an age criterion in forensic dentistry. L. Dental Res. 61: 814-817.

Suchey, J. M. 1979. Problems in the aging of females using the os pubis. Am. I. Phys. Anthropol. 51: 467-470. 
Suchey, J. M., S. T. Brooks, and D. Katz, D. 1986. Instructions for use of the Suchey-Brooks system for age determination of the male os pubis. Instructional materials accompanying male pubic symphseal models of the Suchey-Brooks system.

Suchey, J. M., S. T. Brooks, and D. Katz, D. 1988. Instructions for use of the Suchey-Brooks system for age determination of the female os pubis. Instructional materials acompanying female pubic sumphyseal models of the Suchey-Brooks system.

Szilvassy, J. 1980. Age determination on the sternal articular faces of the clavicula. I. Human Evolution 9: 609-610.

Todd, T. W. 1920. Age changes in the pubic bone. I. The male white pubis. Am. I. Phys. Anthropol. III: 285-334.

Todd, T. W. 1921. Age changes in the pubic bone. II. Pubis of male negrowhite hybrid. III. Pubis of white female. IV. Pubis of female negro-white hybrid. Am. I. Phys. Anthropol. 4: 1-70.

Todd, T. W., and E. W. Lyon, jr. 1924. Endocranial suture closure. Part I. Adult males of white stock. Am. I. Phys. Anthropol. 7: 325-384.

Todd, T. W., and E. W. Lyon, jr. 1925a. Cranial suture closure. Part II. Ectocranial suture closure in adult males of white stock. Part III. Endocranial closure in adult males of negro stock. Am. I. Phys. Anthropol. 8: 23-71.

Todd, T. W., and E. W. Lyon, jr. 1925b. Suture closure. Part IV. Ectocranial closure in adult males of negro stock. Am I. Phys. Anthropol. 8: 149168.

Trotter, M., and R. R. Peterson. 1966. Art'rology. In Morris' Human Anatomy. 12th ed. 317-420. New York: McGraw Hill.

Ubelaker, D. H. 1984. Human Skeletal Remains. 2nd ed. Smithsonian Institution Manuals on Archaeology.

Webb, P. A. O., and J. M. Suchey. 1985. Epiphyseal union of the anterior iliac crest and medial clavicle in a modern multiracial sample of American males and females. Am. I. Phys. Anthropol. 68: 457-466. 